\title{
LILITH O BEATRICE: LA MUJER EN EL FIN DE SIGLO. ARQUETIPOS FEMENINOS DANNUNZIANOS Y SU DIFUSIÓN EN EL MODERNISMO
}

\author{
LILITH OR BEATRICE: WOMAN IN THE TURN OF THE CENTURY. FEMALE \\ DANNUZIAN ARCHETYPES AND THEIR DIFFUSION IN MODERNISM
}

Assumpta Camps

Universidad de Barcelona

\section{RESUMEN:}

Gabriele D'Annunzio fue un conocido escritor y político italiano que introdujo en la literatura italiana el personaje de femme fatale, una mujer que representa la belleza y la sensualidad, cualidades que utiliza para dominar al hombre. Frente a este término encontramos la femme fragile, caracterizada por su entrega y sumisión. Este artículo pretende analizar estos dos arquetipos femeninos en la obra de D'Annunzio y su importancia en la literatura posterior.

\section{Palabras claves:}

Dannunziano, femme fragile, femme fatale, Gabriele D'Annunzio.

\section{Abstract:}

The purpose of this paper is to underline Gabriele D'Annunzio was a well-known Italian writer and politician who introduced the character of femme fatale in the Italian literature, a woman who represents the beauty and the sensuality, qualities which are used in order to control the man. Facing this term, we can find the femme fragile, characterised by her service and devotion. This article aims to analyse these two female archetypes in the work of $\mathrm{D}^{\prime}$ Annunzio and their importance in later literature.

\section{KEY WORD:}

Dannunzian, femme fragile, femme fatale, Gabriele D'Annunzio. 
"Femme fragile" vs. "femme fatale"

"Nunca como ahora las mujeres han tenido tan acusado aspecto

de largas flores en sus tallos, o de maravillosas serpientes erguidas"

Jean Lorrain, Femmes du 1900.

El escenario literario y artístico finisecular nos presenta la oposición entre dos tipos femeninos bien definidos que se presentan en múltiples versiones y recreaciones: la mujer angelical y la mujer fatal. La oposición, herencia de la época isabelina aunque recuperada por el Romanticismo, se consolida como tipo (es decir, como suma de clichés) con Th. Gautier, estructurando la representación de la mujer en la literatura y las artes plásticas durante el Simbolismo-Decadentismo, hasta el punto de transcender a la vida cotidiana de la época.

El primero en hablar de «femme fatale» fue Mario Praz en su ya clásico ensayo $L a$ carne, la muerte y el diablo en la literatura romántica. En él se refería a esa asimilación de Belleza-Muerte de impronta victorhuguiana, a esa recreación de la belleza letal, profunda, terrible, pero también fecunda, a menudo cubierta por el manto de las sombras, que los románticos convirtieron en el tipo de la «belleza turbia» o «contaminada». Fascinados por la «belleza contaminada», la transformaron en un ídolo, como trasposición femenina del héroe byroniano que se había consolidado unos años antes. El Decadentismo heredó, como decíamos, esta visión de la «belleza turbia», pero la enriqueció con una sensibilidad propia, orientada no tanto a sorprender al lector como a sacudirlo moralmente (como también haría magistralmente Baudelaire por ejemplo), mostrando una complacencia por lo horrendo a nivel moral y a menudo también estético y hasta fisiológico, dada su atracción por los cadáveres, vampiros y la belleza pútrida en general. En este sentido, se podría decir que el Decadentismo a menudo "petrarquiza" sobre lo horrendo, atraído por una fascinación por lo femenino que se percibe siempre como un elemento diabólico, y donde el ideal erótico se combina con lo exótico, a menudo de carácter orientalizante. Por tal motivo, el escenario bizantino resulta recurrente en la representación de la "femme fatale", tanto en la literatura como en las artes plásticas. La mezcla de voluptuosidad y misticismo, tan característica en el fin de siglo, corresponde, de hecho, al éxtasis del exotista, siendo el exotismo una proyección fantástica de una necesidad sexual, como se puede apreciar en múltiples ocasiones en Th. Gautier o en G. Flaubert, entre otros. Este "eterno femenino" encarna, a su vez, el Hado para la figura masculina en el fin de siglo. Sugiere una sutil mezcla de voluptuosidad y muerte que se hallaba ya evocada por J. Keats (Oda al ruiseñor), la cual se enriquece con el exotismo estetizante de la segunda mitad del s. XIX proyectándose sobre la representación de un ídolo femenino de belleza fatal para el hombre. Ampliamente presente ya en Gautier y en Flaubert, se desarrolla plenamente en los prerrafaelitas y en Swinburne, para pasar luego a nutrir las recreaciones de Walter Pater, Oscar Wilde o D'Annunzio, quien finalmente lo introduce (no sin trivializarlo en gran medida) en la literatura italiana finisecular.

Las representaciones de la "femme fatale" insisten en su sensualidad y su gran experiencia sexual, pues acumula el saber del mundo, siendo una recreación de la Elena de Troya. No sólo evoca los placeres mórbidos y sacrílegos de un erotismo perverso que trae la perdición al hombre, sino también ciertos rasgos y características físicas que la definen y se hallan habitualmente presentes en todas sus manifestaciones. Así, por ejemplo, destaca su voz, profunda e insinuante, su mirada, fría y cruel, su desdén, su ironía, y hasta su ira (contra el poeta, por ejemplo), su enigmática sonrisa (el referente es la inquietante y ambigua "Gioconda" de Leonardo da Vinci), o su sádica risa, la palidez de su rostro (donde destaca una boca singularmente roja que evoca la sangre) Se halla a menudo envuelta en rosas sensuales, cubierta de perfumes y joyas, y rodeada de una decoración suntuosa y bizantina, exuberante como ella misma: es una diosa. Pero por encima de todo destaca por su movimiento (por contraste con el estatismo de las representaciones de la "femme fragile"), por lo que a menudo se combina su representación con la imagen de la serpiente, el fuego o la danza. “La belle dame sans merci" es un ídolo eterno de una belleza enigmática de voluptuosidad inaferrable, que atrae al hombre igual como puede atraer el abismo, seductora y satánica (como lo fue el héroe byroniano del primer Romanticismo), equívoca y perversa, nueva encarnación de Lilith, que se enriquece en el fin de siglo con la aportación de Sade (a partir de los Poems and Balladsde Swinburne). Al combinar sensualidad y animalidad a menudo se la representa a través de una criatura híbrida (esfinge, como en The Sphinx de O. Wilde, quimera, harpía, sibila, sirena, gorgona o medusa); o bien como tarántula serpiente o vampiro. Mito ambivalente, en el que se combinan vida y muerte, es la llama que atrae y destruye a la vez, proyección de un deseo masculino sometido al canibalismo sexual de la mujer.

Ante el ídolo de la "femme fatale", el hombre se representa en el fin de siglo como un joven inexperto, invirtiéndose la relación tradicional hombre-mujer: del carácter sádico y el rol activo del héroe byroniano pasamos a la complacencia en el masoquismo y la adopción de un rol pasivo respecto a la mujer-diosa, donde se evidencia la obsesión por la figura del andrógino que caracteriza el fin de siglo. Todos los rasgos de la "femme fatale" contribuyen a perfilar esta relación asimétrica entre los sexos, por la cual se acentúa la definición en negativo del hombre finisecular no sólo como joven e inexperto (antítesis de la "belle dame sans merci", mujer que acumula toda la experiencia del mundo), sino claramente como "powerless victim" frente a ella.

El interés por el otro polo de la dicotomía que presentábamos al inicio, la "femme fragile", surge algo más tarde y se desarrolla a partir del prerrafaelismo inglés. Representa un tipo femenino de pureza inmaculada, caracterizado por la bondad, la 
sumisión, la devoción, el espíritu de sacrificio y de renuncia: es la redentora, la mujer ideal, de aspecto angelical, representada habitualmente con una larga cabellera y talle esbelto, como un lirio. A diferencia del otro tipo, en ella predomina la impresión visual antes que su psicología, la representación estática antes que su movimiento. Es sobre todo heredera de la tradición artística de los primitivos (a menudo el autor la presenta a través de referencias anteriores a Rafaello de Sanzio), como Leonardo da Vinci, Botticelli o Donatello, así como los poetas del Duecento o el Trecento. Lirios, guirnaldas de flores (como en la "Alegoría de la Primavera" botticelliana), y jardines bucólicos la rodean; gráciles cabelleras rubias, castas pupilas, largas y cerúleas manos la definen; aparece envuelta en fábulas míticas, vestida de un manto plateado... Su retrato respira la candidez del lirio, la pureza de una "gélida virgo prerrafaelita", la palidez de Selene. En este tipo femenino hallamos un eco no sólo de la Beatrice dantesca, sino también de la recuperación del culto de la virgen, así como una manifestación del neoplatonismo finisecular, que se combina con la condena del materialismo positivista contra el que reacciona una parte del esteticismo ruskiniano de finales del siglo XIX, difundiéndose ampliamente en el Decadentismo.

Entre la "donna angelicata", de pureza inmaculada, y la belleza cruel y perversa de "la femme fatale" que arrastra al abismo, entre la "femme fragile" y todas las representaciones de la "belle dame sans merci" que pueblan el fin de siglo (Hérodias, Cleopatra, Salomé, Salammbó, la Carmen de Mérimée, la Velléda de Chauteaubriand, la Conchita de P. Louys, la Isabella de D'Annunzio .... crueles cortesanas y reinas de la antigüedad, famosas pecadoras, grandes seductoras...), entre Beatrice y Lilith, en fin, se halla anclado el hombre del fin de siglo, atraído, por una parte, por una sensualidad que le conduce al abismo y, por la otra, por un ideal de pureza que le brinda consuelo y redención. Entre el lirio y la serpiente, la mujer finisecular, vista a través del filtro masculino, rehúye representaciones realistas para convertirse en un símbolo, en sentido junghiano, reflejando una relación del hombre con la alteridad femenina que resulta altamente literaturizada y maniquea, anclada en tópicos heredados y recreados a partir de la tradición.

\section{Arquetipos femeninos en D’Annunzio}

La misma dualidad entre "femme fragile" y "femme fatale", la misma dicotomía de lo femenino ante la que se sitúa el hombre, se halla presente en D'Annunzio, un autor que, además de recrear los tópicos finiseculares, los interpretó e introdujo en la tradición literaria italiana. La atracción por la voluptuosidad inaferrable aparece pronto en el escritor abrucense, transformando y modernizando el fuerte sensualismo característico del primer D'Annunzio. El tipo de la "femme fatale" se verá en él enriquecido con las aportaciones de Walter Pater (en especial la sonrisa enigmática de la Gioconda leonardesca), y de Oscar Wilde (sobre todo por el personaje de Salomé y por la esfinge, recreada en The Sphinx). Las primeras muestras de "la belle dame sans merci" dannunziana corresponden a las crónicas del autor publicadas en "Il Mattino" (en concreto, el 18 y 19 de enero de 1893). El motivo persiste en buena parte del D'Annunzio cronista, en escritos publicados alrededor de 1895 en "La Tribuna" y "Cronaca bizantina" que nutren de material literario a sus realizaciones narrativas y poéticas posteriores. Más tarde existen numerosísimas recreaciones de este tipo femenino en la obra, tanto en prosa como y dramática en verso, del abrucense, pero éste se perfila ya en la Pamphila, de Poema Paradisiaco, personaje que recoge, una vez más, toda la experiencia sexual del mundo. El mismo arquetipo se halla recreado en Maia, primer libro de Le Laudi, recuperando la figura misma de Elena de Troya, pero mucho antes que en ella, D'Annunzio lo desarrolla en la serie poética de "las adúlteras" (que no oculta el legado de Th. de Banville), o en Isaòtta Guttadauro, como también en "Due Beatrici" de La Chimera, en contraposición a "Gorgon", composición que les sigue en el mismo volumen poético, entre muchos otro ejemplos. Se recrea, asimismo, en varias de sus protagonistas femeninas: Ippolita, la protagonista de Trionfo della Morte (novela publicada en 1890 y antes conocida como L'Invincibile); la Foscarina de Il Fuoco; la Elena de Il Piacere; La Gioconda; Fedra; la Comnèna de La Gloria; la Basiliola de La Nave, la Pantea del Sogno d'un tramonto d'autunno, la Isabella de Forse che sì, forse che no... Todas ellas son mujeres fatales, mayoritariamente sádicas, estériles, sensuales y sexualmente activas e incluso agresivas. Todas ellas responden al prototipo de la superhembra, que se corresponde al superhombre dannunziano, de una sensualidad igualmente exacerbada, que surge en la misma época, aunque se construye, sin embargo, sobre el modelo nietzscheano. Es a principios de la década de 1890, en la etapa de composición de La Chimera y Poema Paradisiaco, cuando cabe situar la consolidación de este cliché en nuestro autor, que al incorporarlo a su obra manifiesta claros ecos de esa nueva sensualidad finisecular, ampliamente explorada por Flaubert, y enriquecida con el sadismo presente en Swinburne, donde se impone una representación de la relación entre sexos regida por el binomio "voluttà-strage".

Con todo, un rasgo distingue a la "femme fatale" dannunziana de otras representaciones finiseculares de las que deriva o con las que se vincula, en una línea clara de filiación literaria: en el tratamiento del tópico de la "belle dame sans merci" dannunziana se observa a menudo que la relación con el hombre no sólo es de fascinación y seducción del segundo, sino que la mujer utiliza la seducción para atraer al hombre y entregarle el poder, conectando por esta vía dos características fundamentales de D'Annunzio: voluptuosidad exacerbada de carácter agresivo y voluntad de dominio. En efecto, como ya señalaba justamente M. Praz: 
En D'Annunzio la mujer fatal ofrece al hombre por ella fascinado el poder y el imperio: así es en La Gloria, así en La Nave, y así en Fedra [...] la lujuria está estrechamente ligada en $\mathrm{D}^{\prime}$ Annunzio a la voluntad de poder. [...] D'Annunzio intensifica, por lo tanto, el motivo de la superioridad femenina: la mujer no sólo representa el principio activo en la distribución del placer, sino tajeín sólo

gobierno del mundo. La hembra es agresiva, el varón vacila (PRAZ 1969, 275-276).

Este elemento, que vincula a D'Annunzio con Le culte de Moi de Maurice Barrès, tendrá una gran importancia en la difusión del dannunzianismo en el Modernismo, como veremos más adelante. Otro aspecto diferencial a destacar en la recreación dannunziana del tópico de "la belle dame sans merci" es que en algunas ocasiones el autor abrucense vacila entre la "femme fatale" y la "femme fragile", sugiriendo una "coincidentia oppositorum" entre ambas que apunta a una amante ideal, síntesis de las dos. Esto se aprecia, por ejemplo, en Il Piacere, donde se observa por momentos el interés del autor por confundir ambas protagonistas, Elena y María, de un modo tal que supone la alternancia de su posición con respecto a la alteridad femenina, pasando de víctima a verdugo, y de verdugo a víctima.

\section{Mujeres dannunzianas en el Modernismo}

La difusión de la obra de D'Annunzio en el Modernismo catalán fue muy notable, comohemostenidoocasión de tratar anteriormente, porloquenonos detendremosaquía considerar de nuevo este tema. Sin embargo, merece la pena estudiar la influencia que los arquetipos femeninos dannunzianos analizados arriba tuvieron entre los Modernistas, fruto de la fuerte admiración que sentían por el abrucense, el cual se constituyó en un verdadero escritor de moda en Cataluña entre 1898 y 1914 aproximadamente. La representación dannunziana de la mujer tuvo varios canales de difusión entre nosotros. En primer lugar, cabe citar el teatro, cuya influencia se propagó ya sea a través de los comentarios de los estrenos de obras de D'Annunzio en Italia o en París; o bien directamente a partir de los estrenos de dichas obras en Barcelona (recordaremos que éstas se representaban casi exclusivamente en italiano). En segundo lugar, otro canal de difusión fue, sin lugar a dudas, las traducciones, realizadas ya fueran en castellano o en catalán, las cuales abundan entre finales del siglo XIX y principios del XX (principalmente de la obra poética, de las novelas y de algunas narraciones breves). $Y$, en tercer lugar, mencionaremos las imitaciones, es decir, la obra de creación de inspiración dannunziana que recrea tópicos y motivos literarios referidos a la mujer. Cinco autores destacan en la invocación de D'Annunzio en el Modernismo catalán, siendo en todos ellos importante la representación de la mujer desde la óptica finisecular. Se trata de Jeroni Zanné, Ramon Vinyes, Alexandre Plana, Josep Tharrats y Ambrosi Carrion. En ellos se suceden las evocaciones y recreaciones de los dos tipos dannunzianos femeninos que hemos analizado arriba. En la mayoría de casos, es "la belle dame sans merci" quien suscita más interés, aunque no así en Tharrats, mucho más proclive a evocar el otro tipo femenino dannunziano. Entre todos ellos destacará, por su recurrencia y por la significación que éste adquiere, el de una de las mujeres fatales del abrucense: Basiliola. Véamoslo por partes.

Zanné es uno de los escritores más representativos del grupo que a principios del siglo XX se reunía en torno al periódico "El Poble Català", sonetista de pro, y traductor de D'Annunzio en varias y felices ocasiones, así como dannunziano incuestionable. Se inspiró indudablemente en el escritor abrucense para su novela, que permaneció inédita, titulada El fill pròdig, de evidentes resonancias dannunzianas. Ya en el título Zanné remite directamente al abrucense, y en concreto al D'Annunzio de las parábolas que tuvo una gran influencia en el Modernismo catalán. Además de esta resonancia ya de por sí significativa, y del hecho que Zanné cita a D'Annunzio en varias ocasiones en la novela, lo cierto es que toda ella respira una innegable presencia dannunziana. Podríamos incluso afirmar que está escrita siguiendo fielmente la parábola que describen las tres trilogías novelescas dannunzianas, evolucionando de un esteticismo epicúreo (como el que hallamos en Il Piacere), hasta la culminación del nuevo héroe (como en Il Fuoco), en quien se confunden y entrelazan, a lo largo de la narración, ecos más o menos lejanos de Andrea Sperelli, Giorgio Aurispa, Claudio Cantelmo y, por último, Stellio Ėffrena, todos ellos protagonistas masculinos de sus novelas, como es sabido. La presentación de Eugeni Leblond (el protagonista de la novela de Zanné) como un esteta refinado, de vida disoluta, que hereda, por un lado, un temperamento exuberante y, por el otro, una sensibilidad exaltada, nos remite directamente a Il Piacere, a cuyo recuerdo se añade toda la ambientación de la obra, así como el personaje de Aurora, su primera amante, en la que se descubre una clara "evocación helénica" que la vincula a la Elena de la novela de D' Annunzio. Cabe mencionar otros detalles de la vida de Eugeni, como sus viajes, sus aficiones, sus lecturas, etcétera, que evocan Il Piacere. Ahora bien, la segunda de las relaciones sentimentales del protagonista de Zanné, Blanca, apunta por momentos a otra de las novelas del italiano: Il Trionfo della Morte, sobre todo por la dicotomía que Zanné establece entre el héroe masculino y la mujer, dentro del maniqueísmo recurrente en el fin de siglo, reflejando la polaridad Hombre/ Naturaleza, igualmente presente en Il Trionfo..., de claras sugestiones nietszcheanas. Con todo, la aparición de la tercera de las amantes de Eugeni, Margarida, esta vez de innegables resonancias faustianas, introduce un nuevo punto de referencia que acaba configurando una progresión moral -es decir, de Aurora a Margarida, pasando por Blanca- en la educación sentimental del nuevo héroe moderno, tal como la entiende Zanné, siguiendo el ejemplo de las tres protagonistas femeninas de Le Vergini delle Rocce, las cuales establecen en D'Annunzio el proceso de perfección hacia la plenitud 
del superhombre. Y, en efecto, una vez muerta Margarida, Eugeni hallará en el dolor y la soledad el germen de la resurrección, alcanzando la redención a través de la expiación. La imagen final de la novela, una apoteosis del sol sobre las aguas, como símbolo de fecundación y de nueva energía, que bendice a Eugeni en su "soledad heroica", no puede resultar más reveladora de una lectura efectiva de Il Fuoco por parte de Zanné. De este modo, vemos como El fill pròdig describe literariamente un itinerario vital y moral, que desemboca en una profesión de nietzscheanismo, siguiendo en todo momento el ejemplo proporcionado por D'Annunzio en su narrativa, de la que aspira a constituir una suerte de compendio. Para ello recurre a representaciones femeninas de inspiración dannunziana con el fin de mostrar la progresión espiritual del héroe, recreando los tipos femeninos finiseculares que hemos visto arriba.

En lo que respecta a Ramon Vinyes (el "sabio catalán" mencionado por García Márquez), dannunziano de pro en los años anteriores a su exilio a Colombia, destacan principalmente algunas de sus prosas poéticas tituladas L'ardenta cavalcada (1909), volumen que se abría, precisamente, con un lema del abrucense: "L'aspro vin di giovinezza brilla ed arde / ne le arterie umane". En este volumen, como en la mayor parte de la producción -ya sea poética o narrativa- de Vinyes de esos años, se aprecia una influencia de la literatura finisecular de corte perverso y profanatorio, la cual se expresa en un lenguaje arcaizante y decorativista, muy sugestivo y evocador, altamente preciosista. El significado de esta profanación, que no es otro que el de la subversión de los convencionalismos establecidos, se nos revela claramente en el lema dannunziano que abría L'ardenta cavalcada: todo un canto a la plenitud vital y a la fuerza sensual de la juventud. Ahora bien, el volumen no profundiza en esta línea vitalista que el lema sugiere, sino que surge, más bien, de la experimentación en el abanico de temas finiseculares: la imaginería simbolista en Dona, un conte; la complacencia en el sentido de profanación en Conversa; la voluptuosidad de los olores en Els joves Tritons i la parella; el naturalismo patológico en A la llum del capvespre; la "delectatio morosa" en Herodiades o bien en He retrobat el perruquer Oswald; el esplendor de las joyas sobre la piel de la cortesana en Joiells... eboris; el bizantinismo en Minúscules bal-lades lluminoses, etcétera. Un completo repertorio, como podemos ver. Su clara derivación hacia la producción teatral, que tanta importancia tuvo en su trayectoria, se produce hacia 1910 con Al florir dels pomers (Apunt d'ambient). La obra se estrenó el 13 de mayo en el Teatro Romea de Barcelona por la Compañía Borràs.

Existen dos obras dramáticas más de Vinyes que nos remiten también a D'Annunzio y que aquí nos interesan especialmente. Se trata de L'arca i la serp (Poema escènic en 3 actes), y Llegenda de boires (Poema escènic en 3 actes). Para empezar, cabe señalar que se trata en ambos casos de teatro poético, por lo que constituyen ejemplos de realizaciones que ponen en práctica las opiniones del autor sobre este tema. En el aspecto temático, sin embargo, nos interesa subrayar aquí el referente dannunziano en algunos aspectos concretos. En lo concerniente a L'arca i la serp, al margen de la fuerte ambientación bizantina de esta obra y el tono bíblico omnipresente en la misma, cabe destacar el personaje de Cozbi, perfilado como una encarnación de la Basiliola dannunziana. En efecto, Cozbi aparece envuelta en velos y engalanada con joyas y perfumes, ya sea como un vampiro, ya sea como una serpiente, y es capaz de matar con sus ojos como llamas. Se trata, sin duda, de una nueva versión de "la belle dame sans merci". Pero más interesante resulta, en nuestra opinión, la utilización que Vinyes hace del tópico, similar a la que se aprecia en la Basiliola dannunziana presente en la tragedia La Nave. En efecto, la confrontación entre Cozbi y Moisés por el liderazgo del pueblo de Israel se convierte en una lucha dialéctica de carácter simbólico, recurrente en toda la pieza teatral, entre la lujuria y la virtud, la cual se asimilará "tout court" a la dualidad instinto/razón, y, por extensión, Mujer/Hombre. La obra plantea la necesidad de Moisés de pactar con Cozbi, a pesar de todo, pues su discurso resulta mucho más persuasivo, para así culminar su propósito de conducir al pueblo a la tierra prometida. En el plano simbólico, propone una síntesis entre instinto/razón, a la búsqueda de un discurso político basado en la persuasión. Añadamos a esto la complacencia en las imágenes cargadas de sadismo (especialmente en el segundo tiempo del acto III), la presencia de las puestas de sol rojizas ("un cielo de fraticidio", como lo denominará Vinyes, p. 93) que confieren un marco espectacular a la escena, el gusto profanatorio (por ejemplo en las relaciones sexuales entre Zimri, el príncipe andrógino, y Cozbi ante el altar), la visión de la pasión como un estallido irracional e irresistible, o bien como una contaminación (similar a la lepra), la concepción de la purificación tan sólo a través del fuego, etc. Moisés vencerá a la serpiente y reconducirá al pueblo a su destino, pero para ello tendrá que guerrear y matar y, por tanto, dejará de ser puro e inmaculado. Como podemos ver, la obra se inscribe en un repertorio muy del gusto finisecular, que retoma algunas figuras y mitos dannunzianos para recrear y articular a través del teatro un mensaje mesiánico al servicio de los propósitos del autor. El caso de Llegenda de boires es algo distinto. Aquí el referente será La Figlia d'Iorio. En la obra abundan igualmente los tópicos finiseculares. Reencontramos, por ejemplo, la dialéctica pureza/lascivia, representada a través de la oposición entre Bernardeta y el "Home Roig" (el Hombre Rojo) o, si preferimos, la polaridad amor ideal (de Bernardeta y Jan) / pasión carnal (del “Home Roig” por Bernardeta). Hallamos, asimismo, la presencia de otro tópico finisecular recurrente: el de la virgen profanada -léase violada- que será redimida por la maternidad. En este sentido, la mujer se halla anclada en dos únicas condiciones posibles: virgen o madre. El otro polo, ya lo vimos arriba, lo representa la figura de la cortesana, en las múltiples encarnaciones de Lilith. Añadamos que Bernardeta está constantemente caracterizada como una santa, casi como una "madonna": es pura, su matrimonio con Jan es blanco, sueña con tener un hijo concebido igual que Jesús, engendrado no ya 
por el Espíritu Santo a la hora del Ángelus, sino por el malvado "Home Roig" -es decir, el Diablo-, como fruto de una violación, y en sábado, por si fuera poco. Por otra parte, la configuración sádica del "Home Roig" resulta evidente y se halla muy impregnada de ecos dannunzianos ( $\mathrm{y}$ también byronianos, naturalmente): tiene ojos de fuego, se parece a una serpiente, acarrea tras de sí una larga leyenda como seductor, es inquieto, aventurero, eternamente insatisfecho: un ángel caído. Pero, también, es el hijo pródigo que regresa a casa después de una larga ausencia, y finalmente el lobo que muere defenestrado -en una evocación muy directa del teatro de Àngel Guimerà por cierto. En el argumento, la obra recuerda la tragedia de D'Annunzio en varias ocasiones. También lo recuerda la visión de la relación erótica tan sólo desde el ángulo de la profanación (por parte masculina) y del sacrificio (por parte femenina); o bien la presentación de la habitación de Bernardeta como un especie de santuario profanado (en este sentido, cabe destacar la abundancia de elementos litúrgicos presentes en el tercer acto de la obra), así como el gusto por la inversión del mensaje evangélico, del cual Vinyes no puede prescindir, ni tan siquiera para transgredirlo. En efecto, en ella, el santo misterio de la inmaculada concepción se convierte en una broma grotesca, y la imagen icónica de la Purísima pisando la serpiente, cae del pedestal, en una suerte de discurso que cabe vincular estrechamente a las parábolas dannunzianas ampliamente difundidas en el Modernismo catalán a finales del siglo XIX y principios del XX. En un plano más puntual, mencionaremos una constante en Vinyes que remite indefectiblemente a D'Annunzio en toda su obra: la utilización del tópico de las rosas como correlato del placer y la sensualidad. Así, por ejemplo, hablando de Bernardeta, "entre los pastores debe haber quien gime con el deseo de desflorarte" (p. 43); "quien quisiera recordar tus labios evocaría un manojo de rosas rojas" (p. 55); o "perfume del más caro: rosas" (p. 112; la traducción es mía en todos los casos). Para concluir, Bernardeta -la ingenua- se contrapone en la obra de Vinyes a Rosa -la mujer con experiencia-, en una dualidad que, evidentemente, retoma la polaridad entre Maria y Elena, las dos protagonistas femeninas de Il Piacere.

En lo referente al tercer autor que mencionábamos, Alexandre Plana, cabe señalar que se trata de una figura literaria que se incorpora al Modernismo de los ambientes culturales de Barcelona hacia 1909. La temática histórica y mítica, así como la experimentación en el bizantinismo finisecular, constituyen el núcleo principal de la práctica literaria de Plana en los primeros años del siglo XX, bajo la influencia, muy clara en él, de Ramon Vinyes. En eso y en lo concerniente al dannunzianismo, pero a diferencia de cuanto vimos a propósito de Vinyes, Plana remitirá directamente al escritor abrucense, utilizándolo como pretexto para la creación literaria en varias ocasiones, para más tarde distanciase abiertamente de esta influencia. $\mathrm{Al}$ menos en dos momentos nos remite directamente a D'Annunzio. En la primera ocasión, lo hace con el lema que abre el poema "Cleopatra i l'ibis", con el que ganó el premio de la "flor natural" en los Juegos Florales de Olot de 1908: "Sembrami che ne l'aria s'effonda / quel lento odor che lentamente uccide". En este caso, la cita de D'Annunzio sirve al autor para introducir el tema, tan propio del gusto finisecular, de la voluptuosidad de la muerte, en una ambientación poética de fuerte contenido exótico, sugerido por la recreación de la figura de Cleopatra. Podemos leer lo siguiente:

Cleopatra ve una sombra, la muerte, y quiere abrazarla

en su brazos, besarla, disfrutar de ella más y más.

sus labios saboreando el hielo de un beso

gozarán, muriendo, la infinitud del placer.

Unos meses más tarde, sin embargo, la alusión a D’Annunzio es más indirecta y, a la vez, más interesante. En esa ocasión, Plana firma la serie de tres sonetos titulados “El barrer triomf de Basiliola" ("El último triunfo de Basiliola") que publicó el periódico "El Poble Català", cada uno de ellos precedido por una breve introducción en prosa, que venía a ser un resumen del contenido del soneto. Además, cada uno llevaba un lema inicial procedente de la tragedia dannunziana La Nave, la cual, sin embargo, no se mencionaba en ningún momento. En efecto, el referente de La Nave es evidentísimo en las tres composiciones poéticas, que siguen fielmente la trama argumental de la tragedia, como lo era ya desde el mismo título de la serie por la invocación a Basiliola, la protagonista femenina de dicha obra. Ahora bien, más allá de la exploración en la temática decadentista que la tragedia de D'Annunzio ofrece ampliamente, Plana se interesa en esta ocasión por otro aspecto, que vemos aquí muy acentuado. En realidad, no remite a los pasajes de La Nave que presentan un carácter más sensual, de una morbosidad más marcada, sino que, sobre todo, se orienta a recrear literariamente el motivo del sacrificio de esta "belle dame sans merci" llamada Basiliola y la expedición de Marcus Gratico, dos momentos de la tragedia que Plana contempla como dos cumbres de un mismo acto fundacional de la Ciudad futura -en este caso, Venecia, como sabemos. Leemos lo siguiente en los dos tercetos del último de los sonetos:

...Basiliola se lanza

en medio del fuego del ara: se convierte en inmensa

la llama en su cabellos, y en un estallido

de su luz de oro, de sangre y de crepúsculo

nace un perfume, porque nace ahora con el crepúsculo

la inmensa flor de los libres: jla Ciudad!

Basiliola vence, no por su muerte bella y heroica -como reclama al Tribuno Marcus al final de la tragedia-, sino fundamentalmente porqué en su sacrificio se halla el éxito de la empresa imperial de su pueblo. En la interpretación de Plana, esta invocación a La Nave se convierte en un canto apoteósico a la pujanza latina en su fuerza expansiva imperial-nacionalista: “La patria è su la Nave”, repite el coro insistentemente en el epílogo final de la obra, y recoge Plana como lema en el inicio del tercero de los sonetos de la serie. De este modo, Plana se incorpora a la reivindicación de latinismo que conlleva, en la época, toda referencia a D'Annunzio, la cual se halla al servicio de un ideario que 
defiende el proyecto de reconstrucción nacional -es decir, de "creación de la Ciudad futura"-; un proyecto que se empieza a teñir ya claramente de un impulso imperialista como el que se observa pocos años más tarde.

Cuando en 1909 Josep Tharrats publica en Girona su primer volumen, de prosas líricas, titulado Orles, dedica su libro al "maestro Gabriele D'Annunzio". Cuando, bastantes años más tarde, en 1924 para ser exactos, reúna una parte importante de su producción de sonetos -y pensemos que llegó a escribir cerca de cinco mil a lo largo de toda su vida- en el volumen Les ofrenes espirituals, éste se abrirá -como no podía ser de otro modo- con un soneto que se titula "Gabriele D'Annunzio", a la vez que incluirá otro, el soneto XXV del libro, titulado muy significativamente "Paràfrasi", que se inspira directamente en una protagonista femenina de D'Annunzio: Silvia Settala. Todo el volumen, de hecho, transpira dannunzianismo por los cuatro costados, y una particular visión del mediterraneismo que comporta la exaltación de la raza latina y del espíritu pagano, al servicio del ideal de la Ciudad futura. A todo ello cabe añadir la producción literaria inédita de Tharrats, que es mayoritaria, y en la que abundan las referencias directas al italiano, de un modo tal que tenemos que concluir que en ningún otro caso D'Annunzio contribuyó a crear el universo literario de un escritor catalán como lo hizo con Josep Tharrats. La sugestión dannunziana alcanza en el escritor de Girona hasta el punto de inspirarle tres sonetos que quedaron inéditos y se recogen sin fecha en el archivo familiar, aunque cabe situarlos con toda probabilidad a principios del siglo XX. Se trata de sonetos de corte inequívocamente dannunziano, escritos además en italiano, los cuales nuestro autor tituló significativamente "Sonetti d'una sera paradisiaca". Constituyen meros ejercicios poéticos, como también lo eran las traducciones que realizó, compuestos con la misma voluntad: crear una lengua literaria culta, dúctil y refinada, musical y plástica, a través de la asimilación, en este caso, de la poética dannunziana. Este objetivo prioritario comportaba la investigación en temas, imágenes y motivos literarios dannunzianos, los cuales vehiculaban unos determinados contenidos que el autor ponía al servicio de un cierto programa poético y cultural. Con todo, cabe señalar que en Tharrats el sensualismo dannunziano, aunque presente, se halla muy depurado en su alcance subversivo, y permanece más bien circunscrito a un plano experimental, más formal que ético, a diferencia, por ejemplo, de lo que podemos ver en otros escritores catalanes de la época, igualmente impregnados de dannunzianismo, como Ramon Vinyes. Si nos detenemos a analizar la prosa poética, inacabada e inédita, que Tharrats tituló La dansatriu de la cabellera d'ombra, desgraciadamente sin fecha en el archivo familiar, hallaremos plena confirmación de cuanto apuntábamos arriba, y que constituye una rasgo recurrente en Tharrats, por otra parte. En efecto, la bailarina, envuelta en fuego, es ritmo puro y baila desnuda ante la multitud, evocando indiscutiblemente el personaje de la Basiliola dannunziana en la tragedia La Nave, que tanto impacto tuvo en el Modernismo catalán. Sin embargo, en la misma medida que la evoca de un modo indiscutible, se distancia también claramente de ella, ya que Tharrats rechaza insistentemente el aspecto más libidinoso del baile de esta figura, recreación del tópico de la "belle dame sans merci", a la vez que subraya la imagen ideal de la Belleza, cuya contemplación es capaz de elevar el espíritu de los que la contemplan. En efecto, leemos:

parecida a una viviente Salomé exenta de crueldad, que en lugar de danzar trágicamente sobre la sangre humana, aún tibia, se complaciera deliciosamente en la blanda agonía de las flores votivas". Tan sólo un instante, "en el vértigo de la danza, un destello vagamente lúbrico rutila en sus ojos intensos, transmitiendo una alegría sádica a las miradas ávidas de los espectadores,

para cubrirse a continuación púdicamente con la inmensa cabellera. Por el contrario, recordaremos que Basiliola se insinuaba, en cambio, con sus cabellos ardiendo. Lo que Tharrats hace, de hecho, en esta prosa poética es utilizar un tema decadentista para alterar su significado original y convertirlo en una visión decorativista que se nutre de los motivos de las poéticas finiseculares y del tópico de la "femme fatale" arrastrando al lector con su torrente de una prosa rica en sugestiones musicales y plásticas, teñida con la coloracióndeunasensualidadintensayexótica,lacualexploratodoslosregistrosformales posibles acentuando el movimiento y las cualidades proteicas de la danza de la bailarina. La segunda de las prosas poéticas de Tharrats, igualmente incompleta, inédita y sin fecha en el archivo familiar, insiste de nuevo en el tema de la bailarina ?podríamos llamarla? "casta", poniendo de manifiesto que la contemplación estética, que alcanza con la danza un grado superior por la combinación de música, ritmo, movimiento y plasticidad, se presenta siempre en Tharrats en su vertiente apolínea: es una contemplación que purifica, eleva el espíritu, y resulta fuente de inspiración creadora nunca de incitación para los bajos instintos humanos. Leemos lo siguiente:

Bailaba tan maravillosamente y con tanto arte, que ni sus movimientos, ni sus gestos, ni las acciones iniciaban la más mínima lascivia. Y la estética de su danza ponía como un velo espiritual ante los ojos atentos de los espectadores y dotaba de una luz intelectual y creativa a las almas selectas.

En el mismo sentido, los temas decadentistas que el autor recrea se verán impregnados de idealismo y a menudo depurados de connotaciones consideradas "impuras" o "inmorales". Así, por ejemplo, cabe hablar de esta prosa, de corte inequívocamente dannunziano, que se inspira en la trilogía narrativa I Romanzi della Rosa, y en gran parte en Il Piacere, tanto por la carnalidad que desprende la relación entre los protagonistas, Maria Stella y su amante Wilfred, como por el gusto que muestra por las decoraciones bizantinas que se ofrecen como fondo a los amores suntuosos de los protagonistas. En ella se observa que el autor presenta la plenitud de una relación sensual limpia de connotaciones sádicas, que resulta ajena a las novelas dannunzians. Por otro lado,

-


Tharrats recupera en ella un motivo que le resulta particularmente grato, y que se halla indefectiblemente ligado a la inspiración dannunziana en nuestro autor: las manos de la amada. En este caso, se trata de las manos de la protagonista, Maria Stella, las cuales, "infinitamente benignas y sabias... sugerían el recuerdo amable e indeleble de una heroína dannunziana, pues eran muy dignas de ser consagradas en el verbo elocuente del privilegiado poeta italiano" (la traducción es mía): es decir, evocan las manos puras, e igualmente consoladoras para el artista, de Silvia Settala en La Gioconda. Tharrats nos presentaba, en su “Marbre votiu a Gabriele D'Annunzio" un D' Annunzio "trágico y elegíaco". Y si "elegíacos" eran, en líneas generales, los poemas del italiano que fascinaron a Tharrats y le inspiraron su obra poética y sus traducciones, "trágico" será el D' Annunzio que constituye el punto de partida para el único intento en el campo teatral que realizó Tharrats en su carrera: el Assaig tràgic, en un acto -apenas un esbozo de tragedia que recuerda de lejos La Gioconda-, el cual se halla incompleto. Este ensayo, coetáneo de Versions poètiques..., lleva la fecha de 1909, y permaneció inédito, como la mayor parte de la obra del autor. Es de inspiración innegablemente dannunziana y remite a La Gioconda, aunque en Tharrats se subrayará sobre todo el momento en que Edmond regresa arrepentido a los brazos maternales de su sacrificada esposa.

A diferencia de otros dannunzianos de pro de la época, la ejemplaridad del abrucense en Tharrats será larga, y se confirma incluso durante el conflicto bélico europeo, adquiriendo connotaciones raciales y prolongándose al menos hasta la publicación de Les ofrenes espirituals en 1924.

En lo concerniente a Ambrosi Carrión, autor de tragedias y poeta, el modelo dannunziano resulta aún más evidente, si cabe, y se puso de manifiesto de forma quizá más recurrente por la crítica de la época. En su caso, la afinidad entre ambos autores, más allá de centrarse en la recreación de algunos tópicos dannunzianos habituales, como por ejemplo la sensualidad exacerbada, impregnada de misticismo o bien sublimada en heroísmo, hay que buscarla, más bien, en la coincidencia en una experimentación teatral que apunta a la recreación del sentido trágico de la antigüedad griega, lo cual se plantea, en Carrión como en D'Annunzio, como un retorno a los clásicos griegos, en una revisión de los clásicos en clave moderna que nos presenta un mundo de pasiones desatadas y vagas fatalidades que pesan sobre el individuo, recreado sobre la base de las tragedias griegas. Carrion derivó ya hacia estos posicionamientos hacia 1909 con Tribut al mar (Tragèdia en un acte), obra escrita en verso como resultado del impacto de la corriente latinista en el Modernismo catalán. El referente literario inmediato para la propuesta dramática en la que Carrión se inscribe con Tribut... no es otro que D'Annunzio, cuya huella se descubre abiertamente en esta primera tragedia del autor por varios motivos. En primer lugar, porqué explora de un modo similar la recuperación de la temática clasicizante desde una óptica moderna. En segundo lugar, sobre todo por el personaje de Nike, que se inspira directamente en la Basiliola de La Nave. En tercer lugar, por el desenlace de la tragedia, pues la muerte de la protagonista supone la redención tanto de ella misma como de su pueblo. Y, por último, por la vocación mesiánica de esta propuesta dramática de Carrion, de clara filiación dannunziana, pues Carrion se inspira no en el D'Annunzio de La Città... o de La Figlia..., obras todas ellas mucho más valoradas en Cataluña por entonces, sino en el D'Annunzio de La Nave, de claras resonancias imperialistas. En su obra, destaca la utilización de esta nueva "femme fatale", inspirada en la Basiliola dannunziana, y de nombre revelador, al servicio de la voluntad imperialista del protagonista masculino y de la salvación de todo el pueblo. En efecto, Nike es un personaje que arrastra las características propias del tópico de la "belle dame sans merci": joyas, perfumes, larga cabellera, sensualidad, seducción, lascivia... Se trata de una recreación del tópico que insiste especialmente en la morbosidad característica de la belleza contaminada, y en la perversión moral de la protagonista, quien, no obstante, será capaz de sacrificarse heroicamente por su pueblo. El paralelismo de esta obra con La Nave resulta evidentísimo, con la sola diferencia de que aquí el sacrificio que redime a la protagonista y, en consecuencia a su pueblo, no se consuma con la auto-inmolación en el fuego, sino que se produce con su salto al vacío desde el acantilado. En el caso de Carrion, se trata no sólo de contribuir a crear un teatro nacional y poético en catalán, sino un teatro mesiánico. En este sentido, cabe señalar que La Nave ofrecía un mayor grado de ejemplaridad para Carrion. Tribut al mar se perfila como el resultado directo del impacto que tuvo la propuesta neo-trágica de D'Annunzio en la Cataluña de principios del siglo XX.

Para concluir, D'Annunzio constituye un referente cultural ineludible, no sólo para el Modernismo, sino también para buena parte de la literatura catalana contemporánea, incluso en autores que no sospecharíamos que fueran dannunzianos en un principio. Y en casi todos los casos, se observa una utilización de los tipos femeninos recreados por el abrucense en su obra, ya sea poética, narrativa o dramática. Por ejemplo, y sin ánimo de ser exhaustivos, lo reencontramos evocado junto a Rubén Darío, por ejemplo en la primera producción poética de Pere Gimferrer, así como en la novela Fortuny. O bien en algunas prosas del volumen de narraciones breves titulado Mites, de Jordi Sarsanedas, en concreto, en el cuento Dues noies. En lo concerniente a este último punto, resulta interesante destacar no sólo las referencias directas y explícitas a D'Annunzio, sino su influencia en el ámbito estructural del cuento, pues observamos como toda la narración gira alrededor de la dicotomía entre los dos arquetipos femeninos que hemos tratado aquí, los cuales retoman y desarrollan la oposición presente en Il Piacere de D'Annunzio, entre la "donna angelicata" y la "femme fatale". 


\section{REFERENCIAS BIBLIOGRÁFICAS}

Camps, A., La recepció de Gabriele D'Annunzio a Catalunya, Barcelona, PAM, 1996.

----, El Decadentismo italiano en la literatura catalana, Berna, Peter Lang, 2010.

D’Annunzio, G., “La Chimera”, en Versi d'amore i di gloria, Vol. I. Milano, Mondadori.

Hinterhäuser, H., Fin de siglo. Figuras y mitos, Madrid, Taurus, 1980.

Litvak, L., Erotismo fin de siglo, Barcelona, Antoni Bosch, 1979.

Plana, A., “Cleopatra i l'ibis”, en El Poble Català, 14/IX/1908.

----, "El barrer triomf de Basiliola (I-II-III)", en El Poble Català, 22/II/1909.

Praz, M., La carne, la muerte y el diablo en la literatura romántica, Caracas, Monte Ávila Editores, 1969.

----, Il patto col serpente. Paralipomeni di "La carne, la morte e il diavolo nella letteratura romantica", Milano,

A. Mondadori, 1972.

Salinari, C., Miti e coscienza del Decadentismo italiano, Milano, Feltrinelli, 1960.

Sarsanedas, J., Mites, Barcelona, Editorial Selecta, 1954.

Thomalla, A., Die "femme fragile", ein literarischer Frauentypus der Jahrundertwende, Düsseldforf, Bertelsmann $\mathrm{GmbH}, 1972$.

Vinyes, R., Al florir els pomers (Apunt d'ambient), Barcelona, Biblioteca Teatràlia, 1910.

Zanne, J., Novel-les i poemes, Barcelona, Biblioteca Popular “L'Avenç”, nº 126, 1912.

----, Una Cleo i altres contes, edición y prólogo a cargo de Llorenç Soldevila, Barcelona, Edicions 62, Antologia Catalana, no 90, 1978. 